\title{
Two Sides of the Same Coin
}

\section{Unpacking Rainer Forst's Basic Right to Justification}

\author{
Stefan Rummens
}

In his forceful paper, Rainer Forst brings together many elements from his previous discourse-theoretical work for the purpose of explaining how the basic rights enjoyed by citizens in the context of a constitutional regime could be justified. In line with venerable Kantian ideas, Forst argues that our human dignity as persons implies that we are all free and equal normative authorities with regard to the normative orders we are being subjected to. This authority implies that we all have what Forst calls a 'basic right to justification,' which means that we all have a right to participate as equals in the discursive procedures of reciprocal and general justification in which these norms are being determined. This basic right to justification, in turn, serves as the 'single and properly moral ground' 1 for all of the basic rights we enjoy as citizens because, as Forst explains, a commitment to the basic right to justification always necessarily implies a commitment to these other rights as well.

I find Rainer Forst's discourse-theoretical approach overall highly congenial and I also agree with most of the more specific arguments he presents on this particular occasion. I agree that our basic rights should be grounded in a moral manner and that this ground is properly explicated in terms of our dignity and authority as free and equal persons. Nevertheless, I would like to raise two issues of concern that remain after reading his argument. The first issue is perhaps more a matter of clarification. It relates to three different distinctions that Forst introduces in his paper but which, in my view, appear to be related in ways that he fails to thematize. A clarification of these matters is important, however, because they pertain to the primary distinction between the a priori reconstruction of basic rights by philosophers and the discursive construction of basic rights by citizens. My second point is somewhat more critical and concerns Forst's claim that the right to justification can provide a 'single' source for both the private and the public autonomy of citizens. Here, I will argue that this claim is somewhat misleading because the 'right to justification' as understood by Forst is a substantively rich concept which also already comprises what I will call the 'right to choose your own ends.' A more perspicuous presentation of the discourse-theoretical grounding of basic rights should refer to the basic right to justification and the basic right to choose your own ends as two different but inseparable rights - two sides of the same coin - which jointly provide the moral ground for our basic rights as citizens.

1 Rainer Forst, 'The Justification of Basic Rights. A discourse-theorethical approach', Netherlands Journal of Legal Philosophy 45(3), 20. 


\section{Justifying basic rights: a priori reconstruction versus discursive construction}

In his paper, Forst introduces three interesting distinctions. The first one concerns a distinction between 'two different kinds of normative arguments,' ${ }^{2}$ the second one a distinction between 'status-based' and 'reciprocity-based' arguments supporting basic rights ${ }^{3}$ and the third one a distinction between 'two levels of justification and specificity' at which basic rights are being determined. ${ }^{4}$ Forst simply presents these distinctions separately without further discussing the possible connections that might exist between them. Although he thereby clearly assumes that we are dealing here with three different distinctions, my suggestion would be that they represent, in fact, three different versions of the same distinction.

The most basic distinction, in my view, is the first one between 'two different kinds of normative arguments' or, shorter still, 'two kinds of normativity,' which, according to Forst, is typical of all constructivist understandings of moral and legal norms. ${ }^{5}$ The first kind refers to the normativity of the principles and ideas of practical reason. In the case of Forst's theory, these are 'the principle of reciprocal and general justification' and the 'moral notion of free and equal persons as equal normative authorities with a right to justification. ${ }^{6}$ The second kind refers to the normativity of the norms which are generated by the constructivist procedure itself. In the case of the discourse theory of law, these are the norms that are generated within the actual democratic procedures in which citizens jointly justify the legal norms they are being subjected to.

This distinction is interesting because it tells us something about the different roles that can be taken up by philosophers. ${ }^{7}$ Discourse theorists such as Jürgen Habermas or Rainer Forst are mainly concerned with the first kind of normativity. Their aim is to analyze the ideas and principles of practical reason and to develop, more specifically, a rational reconstruction of the basic features of our moral and political language games as practices of reciprocal justification. This reconstruction is a priori in the sense that it tries to analyze the conditions of possibility of these practices and, thus, to determine under which circumstances valid norms can be generated within actual moral or political discourses. This means, in other words, that the first kind of normative arguments aim to reconstruct the preconditions for the construction of norms belonging to the second kind.

The discourses in which actual moral or legal norms are being constructed have to be inclusive in the sense that all people who will be subjected to these norms

2 Forst, 'The Justification of Basic Rights', 13.

3 Forst, 'The Justification of Basic Rights', 22.

4 Forst, 'The Justification of Basic Rights', 23.

5 Forst, 'The Justification of Basic Rights', 13.

6 Forst, 'The Justification of Basic Rights', 13.

7 See also Stefan Rummens, 'Deliberative Justice,' in The Oxford Handbook of Deliberative Democracy, eds. André Bächtiger, John Dryzek, Jane Mansbridge, and Mark Warren (Oxford: Oxford University Press, forthcoming). 
should be able to participate as equal co-authors. This means, in the case of rights and laws, that this procedure has to be open to all citizens and not simply to philosophers. Of course, many philosophers develop all kinds of elaborate theories explaining the specific rights and laws a properly just society should have. From the point of view of discourse theory, however, these theories of justice can never replace the actual public debate between citizens, but merely serve as possibly relevant contributions to that debate. These kinds of philosophers are no longer engaged in an a priori or transcendental reconstruction of practices of justification, but are contributing to these practices as actual participants.

Importantly, discourse-theoretical approaches assume that basic rights can be justified on the basis of normative arguments of both kinds. Indeed, both Habermas and Forst argue at length that basic rights can be grounded in the ideas and principles of practical reason itself. One of the key points of Habermas's Between Facts and Norms is that the basic system of rights, which forms the core of every constitutional regime, can be reconstructed on the basis of discourse-theoretical premises. ${ }^{8}$ Similarly, Forst's point in the paper discussed here is precisely that the right to justification provides the moral ground for the basic rights citizens hold as subjects of the constitutional state. Both philosophers also emphasize, at the same time, that the a priori reconstruction of rights necessarily operates at a very general and abstract level and that actual processes of deliberation between citizens are needed to generate more specific interpretations of these abstract rights. This means, of course, that these rights should also be generally and reciprocally justifiable norms in the second sense of normativity distinguished by Forst. Basic rights can be reconstructed by philosophers as preconditions of deliberative practices of justification. But they are also, at the same time, justifiable within these very practices by the citizens themselves.

The fact that basic rights can be justified in these two distinct ways is less surprising than might appear at first glance. It testifies, rather, of the continuity that exists between the two kinds of normativity under consideration. Forst rightly emphasizes that 'the normativity of constructed norms depends on the prior normativity of the principles and the standing of the agents of construction.' ${ }^{\text {' }}$ As a result, 'one can only get as much normativity out of a procedure as one invests in it from the beginning. ${ }^{\text {'10 }}$ The core normative idea that is doing the bulk of the normative work here is, in my view, the notion of 'reciprocity.' As I will further explain in the next section, the idea of reciprocity controls both the a priori form of the practices of justification and the substantial content of the outcomes that are generated within these practices.

This brief account of the distinction between two sorts of normativity suggests that we now first have a look at the third distinction I mentioned at the outset. 
This is the distinction between two levels of specificity. On the first level, Forst talks about generally defined basic rights such as 'we find in human rights declarations or (somewhat more concretely) in constitutions. ${ }^{11}$ On the second level, 'the particular content of basic rights must be specified discursively' ${ }^{12}$ on the basis of actual moral, political and legal processes of justification. The distinction between these two levels of specificity has been thematized by Forst on several earlier occasions. Thereby, he has usually labelled it the distinction between 'minimal' or 'fundamental' justice on the one hand and 'maximal' or 'full' justice on the other. ${ }^{13}$ These labels indicate that accounts of minimal justice are essentially concerned with characterizing the general outlines of a minimal or fundamental structure of justification which needs to be in place in order for people to be able to actually engage in discursive processes of will-formation which allow them to develop a more maximal or full account of justice for their own society.

In my view, the distinction between the two levels of specificity essentially coincides with the distinction between the two sorts of normativity. When philosophers develop a minimal account of justice they are trying to determine the minimal conditions of justice that have to be met before actual processes of discursive justification can get off the ground. A minimal account of justice at the first level is therefore an a priori reconstruction of the conditions of possibility of the discursive practices of justification which, at the second level, provide more specific content to these a priori requirements of justice.

Of course, specific human rights declarations are already significantly more specific than the 'abstract scheme of rights' which Habermas reconstructs in Between Facts and Norms or the still general list of rights reconstructed by Forst in his present paper. This shows, I believe, that human rights in a sense occupy the grey zone that exists between the a priori reconstruction of the discourse theorists and the actual processes of lawmaking by citizens. Human rights declarations are no longer entirely a priori in the sense that their specific formulations already reflect a significant amount of historical contingency. As a result of this (limited) contingency, human rights declarations are not entirely immune to discursive challenges in the name of reciprocity. At the same time, however, human rights are indeed deeply 'congealed and solidified' - to use Forst's felicitous phrase precisely because they are much more general and abstract than more specific forms of legislation.

Although human rights illustrate that the boundary between the a priori reconstruction and the discursive construction of basic rights is blurred, they do not undermine the distinction itself. A blurred boundary is a boundary nonetheless and the existence of the grey zone does not detract from the fact that some arguments are clearly on one of the two sides of the boundary. At the same time, the

11 Forst, 'The Justification of Basic Rights', 23.

12 Forst, 'The Justification of Basic Rights', 23.

13 See, for instance, Rainer Forst, 'Two Pictures of Justice,' in idem, Justice, Democracy and the Right to Justification. Rainer Forst in Dialogue (London: Bloomsbury, 2014). 
distinction between the general level of justification of human rights and the more specific level of justification of ordinary legislation does not constitute a distinction that adds something essentially new to the primary distinction between reconstruction and construction. The second distinction operates on the same continuum as the first one.

This brings us, finally, to the remaining distinction introduced by Forst, the distinction between status-based and reciprocity-based arguments for basic rights. I must concede that I find this distinction the least tractable of the three. Its nature and its purpose remain somewhat obscure. Forst defines a status-based argument as one that 'shows how certain basic rights are necessary to institutionalize and secure the very status of being a justificatory equal free from legal, political or social domination. ${ }^{14}$ A reciprocity-based argument, in turn, is one that 'shows how certain rights claims cannot be reciprocally and generally rejected among equal justificatory authorities. ${ }^{15}$

In my view, one of the main problems with this distinction is that the idea of 'reciprocity' does not merely take centre stage in the second type of argument, but actually already does all of the normative lifting in the first type of argument as well. The idea of reciprocity is here somewhat hidden, but nevertheless clearly present through the concept of non-domination. As Forst explains earlier on in the paper, the idea of persons being free from domination means for him that persons should not be subjected to norms that are not reciprocally justifiable. ${ }^{16}$ The central role of the idea of reciprocity that is thus indirectly present in the first type of argument, clearly reveals itself when we look at the way in which Forst argues for the right to individual liberty, a right which he considers to be a prime example of the kind of rights that are justified by status-based arguments. In his reconstruction of this right, Forst claims that

'individual liberty is justified by the basic respect for others as normative equals who would be subjected to domination if some members of society were in a position to define the liberty of others in terms of reasons that can be reciprocally and generally rejected, for example in terms of religious reasons that are not sharable or paternalist considerations that purport to reflect the "true interests" of others who do not share them. ${ }^{17}$

How this type of reasoning differs from a reciprocity-based argument is unclear. In both cases the fact that certain rights cannot be reciprocally rejected seems to do all of the normative work. The claim by Forst that reciprocity-based arguments 'do not point directly to the status-implication of certain rights as does the first justificatory strategy' is also not very helpful in clarifying the matter. The main reason for this is that the concept of 'status' also remains rather underdeveloped. 
According to Forst, the right to individual liberty and the right to freedom of expression are examples of rights that refer 'directly' to our status as equal normative authorities. In contrast, the right to religious liberty or the freedom of artistic expression belong to the group of rights that do not point to this status directly. Something probably escapes me, but to me, this distinction seems moot.

The only way in which I could try to make sense of the distinction between status-based and reciprocity-based arguments is again in terms of the primary distinction between the a priori reconstruction and the discursive construction of basic rights. In the reconstructive phase, philosophers are analyzing and unpacking the principle of reciprocal justification and the idea of persons as free and equal authorities. An a priori analysis of the conditions of possibility of our moral and political justificatory practices thereby reveals that our status as equal participants in these practices necessarily presupposes a commitment to basic rights. In the constructive phase, it is subsequently up to the citizens themselves to make use of their status as normative authorities to engage in actual political discourses allowing them to construct more specific interpretations of these basic rights which are generally and reciprocally justifiable. This reformulation of the distinction between the reconstructive and constructive justifications of basic rights shows in what sense the former could perhaps be understood as a form of status-based justification and the latter as a form of reciprocity-based justification.

My own understanding of Forst's distinction would imply that all basic rights could be justified in both a status-based and a reciprocity-based manner. This follows from the fact that - as indicated before - all basic rights can be justified in both an a priori reconstructive and a discursive constructive manner. This implication seems to pose a problem, however, since it fits badly with Forst's claim that the two kinds of arguments he distinguishes map onto two distinct groups of basic rights, whereby one group contains rights that can be grounded in a statusbased manner and the other group rights that can be grounded in a reciprocitybased manner.

In response, I would like to indicate that the problem seems to be mitigated by the fact that the two groups of rights are perhaps not as distinct as Forst himself suggests. In fact, the group of rights he associates with reciprocity-based arguments seems to contain rights which are more specific versions of more general counterparts in the group associated with the status-based arguments. The latter contains the right to personal liberty, whereas the former specifies this into, for instance, a right to religious liberty. The latter contains the freedom of expression, whereas the former specifies this into, for instance, the freedom of the press or the right to artistic expression. This relation between the two groups of rights, whereby the one is the more specific counterpart of the other, fits again very well with the primary distinction I have in mind. As argued, arguments pertaining to the a priori reconstruction of basic rights operate at a more general and abstract level than the arguments pertaining to the discursive construction of basic rights. 
On the basis of these considerations, I would like to conclude that the distinction between two forms of normativity, the distinction between two levels of specificity and the distinction between status-based and reciprocity-based arguments should be understood as three different versions of one primary distinction. This primary distinction concerns the difference between the a priori reconstruction of basic rights by philosophers and the discursive construction of basic rights by citizens. Its omnipresence illustrates that this primary distinction effectively constitutes a defining trait of the discourse-theoretical approach to basic rights.

\section{The right to choose your own ends}

My second point concerns the thesis regarding the co-originality of human rights and popular sovereignty, or, alternatively, the co-originality of the private and public autonomy of citizens. In this regard, I generally agree with Rainer Forst's criticism of Jürgen Habermas's reconstruction of this thesis. According to Habermas, the combination of the medium of law with the discourse principle (D) - stating that the validity of norms is constituted by the consensus that could be reached through reasonable deliberation - provides the dual source that grounds the abstract scheme of rights protecting both forms of autonomy. ${ }^{18}$ As I have argued elsewhere, ${ }^{19}$ I agree with Forst that Habermas fails to appreciate that the normative lifting in this reconstruction is essentially done by the discourse principle rather than by the medium of law and that, moreover, the discourse principle can only do this work if it is understood as a genuinely moral principle rather than, as Habermas does, a mere principle of validity. Consequently, I find Forst's own attempt to ground the private and public autonomy of citizens in the right to justification as a properly moral principle markedly superior to Habermas's original approach.

In spite of my general agreement, I am less convinced, however, by Forst's additional claim that the right to justification provides a 'common normative ground that explains [the] common origin'20 of the private and public autonomy of citizens. Forst is right that Habermas's 'dual source' approach is not convincing, mainly because the medium of law as such does not play the foundational role Habermas ascribes to it. Nevertheless, I would like to submit that the basic right to justification - as the properly moral alternative for the discourse principle - is not as 'singular' a source as Forst makes it out to be.

The basic right to justification is in itself a quite substantive concept that needs to be further unpacked. This unpacking reveals that Forst - without explicitly acknowledging it - relies on the typically 'dual' structure that characterizes the authority of human persons in the modern age. The basic right to justification

19 Stefan Rummens, 'Debate: The Co-Originality of Private and Public Autonomy in Deliberative Democracy,' The Journal of Political Philosophy 14, no. 4 (2006): 469-81. 
captures our authority as equal co-authors of the norms that structure our social world. The flipside of this authority with regard to the social word is, however, the authority we have with regard to our own private lives. This second and complementary form of authority is best captured by what I would like to call the right to choose our own ends. This is the right which allows us to make our own choices with regard to our own subjective world without thereby having to justify these choices to others. I thereby do not mean to suggest that the right to choose our own ends implies a commitment to the ethical ideal of leading our lives in a maximally autonomous way. In my understanding, this right is compatible with the choice to lead life in line with some traditional religious practice. Importantly, however, the decision to lead your life in accordance with this religious practice is your own and cannot legally be imposed upon you by others.

My main criticism with regard to Forst's discourse-theoretical reconstruction of basic rights is that his reliance on the basic right to justification is, in fact, a reliance on two different but inseparable rights at the same time. The basic right to justification, as he understands it, is a package which contains not only the basic right to justification more narrowly construed as the right to participate in the practices determining our moral and legal norms but also the different but inseparable right to choose our own ends in our own private spheres. This dual structure already clearly shows up at the beginning of Forst's paper when he first characterizes the basic right to justification, the idea of non-domination it contains and the basic rights it gives rise to. The basic right to justification is clearly not only a right to participate, but also a right to ward off domination by others.

'The basic right to justification implies not only political rights of participation, but all of those rights that grant you the normative power to ward off and overcome various forms of domination or unjustifiable subjection. ${ }^{21}$

The same duality returns within the concept of non-domination itself. Although Forst distances himself from a neo-republican understanding of the concept by emphasizing that it refers, in his understanding, also to a status activus in which people can co-author the norms structuring society, he thereby does not abandon the more 'passive' understanding of non-domination as a form of individual freedom which allows us to choose our own ends.

'Freedom from domination not only means being respected as someone who enjoys a legally, politically and socially non-dominated equal status secured by certain rights; it also means that whether you enjoy this status or not is not something that is decided by others without the possibility of your involvement.'22 
As Forst already announces on these very first pages, the very same duality will therefore also return within the structure of the basic rights themselves.

'Basic rights are not just rights to be passively protected in one's status as a legally, politically and socially non-dominated person; they are, in a reflexive sense, also basic rights to determine the rights and duties that define this status. $^{23}$

That Forst's reconstruction of the basic rights as grounded in the right to justification relies in an ineliminable manner on our right to choose our own ends can be shown as follows. To start with, it is important to appreciate that our right to justification is a very demanding right in the sense that not just any kind of justification will do. Forst imposes clear constraints on the kind of justification that we are entitled to and captures these constraints with his criteria of 'reciprocity' and 'generality.' It is instructive, next, to have a closer look at what the requirement of 'reciprocity' consists in according to Forst.

'Reciprocity means that no one may make demands that he or she denies to others and no one may impose his or her non-generalizable views, interests or values on others.' 24

This criterion functions as the equivalent of Habermas's principle of universalizability (U), which states that reasonable consensus can only be reached on the basis of norms that give equal concern to the interests and values of all people affected by the norm. ${ }^{25}$ For Forst, similarly, the idea of reciprocity expresses an ideal of impartiality which assumes that the interests and values of the individual participants in the debate matter. They matter, more precisely, in the sense that all individuals enjoy a prima facie right to choose their own ends in accordance with their own interests and values. This prima facie right can be trumped only on the basis of good reasons referring to the equal freedom of others to choose their own ends.

Because the ideal of reciprocity implicitly presupposes our right to choose our own ends, it comes as no surprise that the idea of reciprocity does most of the normative work in Forst's reconstruction of the basic rights, not only when he uses the so-called reciprocity-based arguments, but also when he uses the socalled status-based arguments. In the previous section I have, for instance, already quoted the argument which Forst uses to support the right to individual liberty. Here, the gist or the reasoning is that our liberty cannot be constrained on the basis of reasons that can be 'reciprocally rejected' 26 because that would otherwise lead to an unacceptable form of domination. This reasoning thereby

Forst, 'The Justification of Basic Rights', 14.

Jürgen Habermas, 'Discourse Ethics: Notes on a Program of Philosophical Justification,' in idem, Moral Consciousness and Communicative Action (Cambridge: MIT Press, 1990), 43-115.

6 Forst, 'The Justification of Basic Rights', 23-24. 
illustrates again that our equal right to choose our own ends provides the yardstick that determines which forms of justification are acceptable and which are not. The fact that individual liberty can be grounded in the right to justification is thus not surprising: this type of liberty simply reflects our authority to lead our own lives as we see fit, an authority that is already contained in the idea of reciprocal justification itself. To repeat an earlier quote from Forst himself: 'one can only get as much normativity out of a procedure as one invests in it from the beginning.' 27

To be clear, my critique of Forst does not target his reconstruction of the basic rights itself. Although the unpacking of the right to justification presented here might suggest that there is a certain circularity in the argument for basic rights (what comes out, is already presupposed), I personally do not object to this kind of circularity. The idea of a discourse-theoretical reconstruction is not to come up with a solid 'foundation' for basic rights, it is merely to present a perspicuous overview of how the different core ideas and principles of practical reason that constitute our practices of justification are intertwined. My only problem with the way in which Forst presents his reconstruction of basic rights is that it onesidedly focuses on our authority in the social world at the expense of our authority in the subjective world and thus produces a somewhat unbalanced account of the normative core of our system of basic rights.

My suggestion that the source of these basic rights has a dual structure should, however, not be misunderstood. My claim is not that there are two different and separable sources for basic rights. The right to justification and the right to choose our own ends are two different but, at the same time, inseparable rights. They do not represent two different coins, but rather two sides of the same coin. Their inseparability means that on a properly Kantian or discourse-theoretical understanding of these rights, the two mutually presuppose each other. Our right to choose our own ends is always a qualified right in the sense that it is limited by the equal right of others to also choose their own ends. This limit is furthermore not an a priori boundary, but a boundary that can only be specified on the basis of actual discursive procedures in which we all exercise our equal right to justification. Explaining how, the other way around, the basic right to justification also presupposes the right to choose our own ends is equally straightforward. If we start from the basic right to justification, it is immediately clear that such an equal right only makes sense - can only sustain the hope for a reasonable agreement - if we accept that not all forms of justification are legitimate, but that justifications will have to be reciprocally acceptable in the sense of giving equal concern to the interest and values - the ends - of all people involved.

Forst's one-sided focus on the basic right to justification is understandable to a certain extent in the sense that he wants to show in what way discourse theory provides a corrective to Kant's original grounding of basic rights. He presents the 
basic right to justification explicitly as an alternative to Kant's 'innate' or 'original' right of persons, which Kant characterizes as follows:

'Freedom (independence from being constrained by another's choice), insofar as it can coexist with the freedom of every other in accordance with a universal law, is the only original right belonging to every man by virtue of his humanity.'28

Here, Kant clearly focuses on the side of the coin which represents our (qualified) right to choose our own ends. The discourse-theoretical corrective that Forst proposes emphasizes that the limits between my own freedom and the freedom of the other need to be drawn in actual discursive practices in which autonomous human beings exercise their basic right to justification. This addition is indeed an important improvement of the original Kantian view. At the same time, however, the corrective should not lead us astray in thinking that the right to choose our own ends could simply be reduced to the right to justification or that our authority as authors of our own lives could be reduced to our authority as co-authors of norms in the social world. These two forms of authority are equally important and equally original and represent two inseparable yet irreducibly different aspects of our dignity as human persons.

Although the dual structure of our human authority is ineliminable, it is true that from a broader historical perspective this human authority can appear as a 'singular' source. Human authority appeared with the advent of the modern age and the disappearance of divine authority as the typically premodern source that decided how human life should be organized. ${ }^{29}$ In the words of the French philosopher Claude Lefort, this historical transition testifies

'to the disappearance of an authority which subjugated each and every individual, to the disappearance of the natural or supernatural basis which, it was claimed, gave that authority an unassailable legitimacy and an understanding both of the ultimate ends of society and of the behaviour of the people it assigned to specific stations and functions. 30

In the premodern era, divine authority controlled our public as well as our individual lives. Both were inextricably intertwined and the distinction between the private and the public sphere as we now know it did not properly exist. The transition to the modern age is therefore characterized by two simultaneous changes with regard to the ultimate sources of authority. On the one hand, divine authority has been gradually replaced by human authority. In that historical sense, there is now indeed a new 'singular' source of authority. On the other hand, however, human authority immediately took on a dual structure for which there is no 
counterpart in the premodern world. As private individuals, we have assumed authority over our own lives and are now free to choose our own ends. As members of society, we have claimed joint authorship over our moral, political and legal norms and now decide for ourselves how we want to organize our irreducibly pluralistic communities.

The point of Forst's discourse-theoretical reconstruction of basic rights is to determine the moral core which grounds - in a groundless manner - our modern moral and political practices of justification. My claim is that his reconstruction is generally convincing but that there is still room for some improvement. Most importantly, his current account regretfully glosses over the dual structure which characterizes this moral core and which constitutes, in fact, a defining feature of our modern condition. Human authority is the new source which replaces divine authority, true enough, but this source is best understood as a coin with two sides. Our basic right to justification as members of the social world has, as its inseparable flipside, our basic right to choose our own ends as private individuals. 